\title{
Assessment of Civil Engineering Students' Exposure Levels to Active Learning Strategies in the UAE
}

\author{
Melinda J. B. Albuquerque ${ }^{1}$, Francisco Daniel B. Albuquerque ${ }^{2}$ \\ ${ }^{1}$ Independent Education Consultant \\ Al Ain, UAE \\ mbiggs4@gmail.com \\ ${ }^{2}$ United Arab Emirates University \\ UAEU Campus, Al Ain, UAE \\ daniel@uaeu.ac.ae
}

\begin{abstract}
Active learning environments are recognized as producing well-established benefits in terms of student learning and higherorder thinking skills. The educational system of the United Arab Emirates (UAE), historically characterized by passive learning, is beginning to focus on active learning. In light of these changes, this study aims to answer the following questions: i) What well-known, easily-implemented active learning strategies have Civil Engineering students from the United Arab Emirates University (UAEU) experienced in their classes? ii) How often have they experienced those same strategies? iii) Is there an existing benchmark for expected student exposure to active learning strategies in active learning environments? and if so, iv) How does this study's results compare to that benchmark? A survey questionnaire containing ten well-known, easy-to-implement active learning methods was created and completed by 174 undergraduate Civil Engineering students at the UAEU. Results were assessed relative to an implementation benchmark from Froyd's work and typical characteristics of active learning environments. Findings reveal that while the UAEU's Civil Engineering classrooms are utilizing most of the surveyed active learning strategies, there is still room for improvement, as several of the strategies' frequency of usage can be considered lower than desired relative to the ease of implementation standards suggested by the benchmark selected (i.e., Froyd's work) and the high levels of discussion, collaboration, and problem-solving characteristic of active learning environments.
\end{abstract}

Keywords: Civil Engineering, Active Learning, Exposure, UAE

\section{Introduction}

\subsection{Background}

The educational system of the United Arab Emirates (UAE) [1-4], is steadily changing and increasingly focusing on active learning strategies characteristic of 21st century skills such as critical thinking, analyzing, and problem-solving [5-8]. In spite of the well-established benefits produced by active learning environments [9-11], active learning remains a broad, often vaguely-defined concept [12]. This study's authors utilize Bonwell and Eison's definition of active learning - involving students in doing things and in thinking about the things they are doing [9]. In active learning environments, students are invited to participate in the learning process through various means: discussions, brainstorming, hands-on activities, presentations, experiments, and simulations, to name a few $[9,13]$. In sum, learning environments in which students are given ample opportunity to interact with the information they are intended to learn are aligning themselves with active learning.

\subsection{Problem Statement}

The UAE's recent intentional shift toward active learning is important in the nation's ability to compete in the global market, as current times require critical thinking and problem-solving skills in the workplace. However, due to the UAE's historical reliance on passive learning strategies, the majority of its Emirati graduates are seen as unable to meet the demands of modern-day employers [14] and are often described as "over-reliant on memorization; ill-equipped for independent learning" [15]. Furthermore, it has been said that many Emirati students are not ready for university and do not possess the needed skills for higher-ordered thinking such as analyzing, debating, comparing, or reflecting [16-18]. Research 
highlighting the UAE's recent shift toward active learning is still few in number and focus on university-level Emirati students who are female or studying English. These studies looked at students' overall learning experiences (primarily related to passive learning) and ways students are beginning to adapt to active learning strategies [2, 15, 19-21]. However, there is no known research to date that focuses on the amount of exposure to active learning strategies that Emirati students have had or are currently experiencing in their classes.

\subsection{Objectives}

This research intends to provide insight into the amount of exposure Civil Engineering students at the United Arab Emirates University (UAEU) have to well-known, easy-to-implement active learning strategies. This study specifically aims to answer the following questions: i) What well-known, easily-implemented active learning strategies have Civil Engineering university students experienced in their university classes? ii) How often have they experienced those same strategies? iii) Is there an existing benchmark for expected student exposure to active learning strategies in active learning environments? and if so, iv) How does this study's results compare to that benchmark?

\subsection{Research Significance}

This research comes at an opportune time and is of particular interest given the UAE's Vision 2021 National Agenda, which "emphasizes the development of a first-rate education system, which will require a complete transformation of the current education system and teaching methods" [22]. The current study may help the UAE assess its progress in terms of its goal. The study's specific focus on university students is relevant in assessing the UAE's pursuit of its educational goals, as university students are the closest to becoming professionals in their fields and entering the global marketplace; thus, knowing what educational strategies this group is exposed to sheds light on where a nation stands in terms of its production of globally-competent graduates.

\section{Method}

\subsection{Data Collection}

One-hundred and seventy-four undergraduate UAEU Civil Engineering students - 148 females and 26 males participated in this study. Students were reached via a self-administered survey based on their enrolment in two courses taught by the co-author: Transportation Engineering (CIVL 330) and Highway Engineering (CIVL 433). At the time of taking the survey, the student sample consisted of 93 fifth-year students, 51 fourth-year students, 26 third-year students, and 4 second-year students, of which 160 were Emiratis and 14 were non-Emiratis. The survey questionnaire was administered in Fall 2019 and Spring 2020. Students in Spring 2020 were asked to complete the questionnaire based on their UAEU experience prior to the coronavirus disease 2019 (COVID-19) pandemic, which shifted all classes to online learning.

\subsection{Survey Questionnaire Preparation}

In order to answer the first and second research objectives, the authors developed a list of ten active learning strategies, as shown in Table 1. These strategies were chosen based on four points, with the first three being taken from Froyd's work [23]: i) relevance: applicable to nearly all fields of study, with some being more expected in science, technology, engineering, and mathematics (STEM) courses, ii) resource constraints: require little to no additional resources, iii) comfort: require little to no training and are easily adapted into instructors' regular teaching practices, and iv) simplicity: simple to describe and ensure student comprehension.

A self-administered survey questionnaire was then created, which contained two parts. Part 1 consisted of questions regarding student demographics: nationality (Emirati and non-Emirati choice options), gender, year in university, and student UAEU identity number. Part 2 consisted of questions regarding students' exposure to the list of selected active learning strategies, as shown in Table 2. It is important to note that the questionnaire purposely asked whether students have experienced the strategies in their UAEU classes and not only in their UAEU Civil Engineering classes. The intent was for students to consider their UAEU career as a whole when responding so as to give a better picture of their entire university 
experience. However, since most students were fourth- or fifth-year students, most of their UAEU career involves courses specifically related to the Civil Engineering program.

A pilot survey involving 34 students was administered to identify any student misunderstanding related to survey questionnaire content. Subsequently, a few writing and formatting adjustments to the questionnaire were made. The questionnaire was then reassigned to the same 34 students in order to compare consistency of their answers between the first time they completed the questionnaire and the second. This way, the accuracy of their responses could also be verified. It was certified that students' responses were consistent in regards to their exposure levels to each strategy investigated.

The questionnaire was printed and handed out to students in Fall 2019 and Spring 2020. Once completed, the results were entered into a database, reviewed, and evaluated by the study's authors.

Table 1: Summary of Questionnaire Strategies

\begin{tabular}{clcl} 
Strategy & \multicolumn{1}{c}{ Definition } & Strategy & \multicolumn{1}{c}{ Definition } \\
\hline \hline Class Discussion & $\begin{array}{l}\text { Discussing/debating topics } \\
\text { as an entire class }\end{array}$ & Presentation & $\begin{array}{l}\text { Presenting information to } \\
\text { instructor/peers/others about a topic }\end{array}$ \\
\hline In-Class Group Work & $\begin{array}{l}\text { Working together in small } \\
\text { groups during class to } \\
\text { complete a task }\end{array}$ & Project & $\begin{array}{l}\text { Working on a project/task that } \\
\text { requires work outside of class }\end{array}$ \\
\hline Computer Simulation & $\begin{array}{l}\text { Using computer simulation } \\
\text { programs }\end{array}$ & $\begin{array}{c}\text { Real-World Problem } \\
\text { Solving }\end{array}$ & $\begin{array}{l}\text { Solving real-world problems that } \\
\text { require students to guide themselves } \\
\text { through the process of finding a } \\
\text { solution (i.e. instructor does not } \\
\text { directly explain the steps students } \\
\text { need to take) }\end{array}$ \\
\hline Experiment & $\begin{array}{l}\text { Making a discovery, testing } \\
\text { a hypothesis, and/or } \\
\text { demonstrating a known fact }\end{array}$ & Guest Speakers & $\begin{array}{l}\text { Listening to/speaking with guest } \\
\text { speakers other than the course } \\
\text { instructor during class }\end{array}$ \\
\hline \multirow{2}{*}{ Peer Teaching } & $\begin{array}{l}\text { Teaching class } \\
\text { concepts/topics to peers } \\
\text { during class }\end{array}$ & $\begin{array}{l}\text { Field Trip / Field } \\
\text { Experience }\end{array}$ & $\begin{array}{l}\text { Taking a trip to a real-life setting } \\
\text { outside of class to experience learning }\end{array}$ \\
\hline
\end{tabular}

Table 2: Part 2 of Questionnaire Format

\begin{tabular}{lll} 
Described Strategy & \multicolumn{1}{c}{ Question } & \multicolumn{1}{c}{ Answer Choices } \\
\hline \hline & How often is this strategy used in your & Always (every week) \\
$\begin{array}{c}\text { Strategy Title and } \\
\text { Description }\end{array}$ & UAEU classes? & Often (every other week) \\
\cline { 3 - 3 } & & Not Often (maximum 3 times per term) \\
\cline { 3 - 3 } & & Never \\
\hline
\end{tabular}

\subsection{Benchmark for Evaluating Student Exposure to Active Learning Strategies'}

In order to answer the third and fourth research objectives, the authors selected Froyd's work on promising teaching practices in undergraduate STEM education as a benchmark for implementation standards of teaching practices [23]. It should be noted that, to the author's knowledge, there is not a specific benchmark for how often each active learning strategy should be practiced in an active learning classroom. However, Froyd's work was chosen as it contains a rubric for evaluating teaching practices with respect to clear implementation standards, as shown in Table 3, and an evaluation of eight promising teaching practices, which include active learning, with respect to those implementation standards, as shown in Table 4 . This information was important as it shed light on how easily active learning strategies can be implemented, which, when coupled with the knowledge of what characterizes active learning environments in general, allowed authors to gauge whether a strategy's frequency of usage was a strong or weak point. Namely, if a strategy is an essential quality of active learning 
environments and is also easy to implement, one would expect it to be frequently utilized in the classroom; thus, if this is not the case at an institution, it may be considered a weak point.

Table 3: Rubric for Evaluating Promising Practices against Implementation Standards (adapted from Froyd 2008)

\begin{tabular}{ccl}
$\begin{array}{c}\text { Evaluative } \\
\text { Rating }\end{array}$ & \multicolumn{1}{c}{$\begin{array}{c}\text { Implementation } \\
\text { Standards }\end{array}$} & \multicolumn{1}{c}{ Description } \\
\cline { 2 - 3 } Strong/High & Relevance: & Applicable to almost every STEM course \\
\cline { 2 - 3 } & Resource Constraints: & Require little to no additional resource investments \\
\cline { 2 - 3 } Good & Relevance: & $\begin{array}{l}\text { Adaptation will not require extensive training, faculty can adapt } \\
\text { practice in steps, almost all of the additional effort occurs during } \\
\text { transition to new practice }\end{array}$ \\
\cline { 2 - 3 } & Resource Constraints: & Require additional resource investments \\
\cline { 2 - 3 } & Comfort: & $\begin{array}{l}\text { Adaptation would be enhanced by training that requires several days, } \\
\text { faculty typically adapt practice all at once, little additional effort is } \\
\text { required after transition }\end{array}$ \\
\cline { 2 - 3 } Fair/Low & Relevance: & Applicable to a minority of STEM courses \\
\cline { 2 - 3 } & Resource Constraints: & Require significant additional resources \\
\hline \multirow{2}{*}{ Comfort: } & $\begin{array}{l}\text { Adaptation will require significant adjustments in practice, will require } \\
\text { practices that are not a part of typical faculty repertoire, will require } \\
\text { ongoing additional effort, even after transition }\end{array}$ \\
\hline
\end{tabular}

Table 4: Summary of Promising Practices and their Evaluation (adapted from Froyd 2008)

Promising Practice

\begin{tabular}{|c|c|c|}
\hline 1 & Prepare a Set of Learning Outcomes ${ }^{\mathbf{a}}$ & Strong \\
\hline 2 & Organize Students in Small Groups ${ }^{\mathbf{b}}$ & Strong \\
\hline 3 & Organize Students in Learning Communities & Fair \\
\hline 4 & Scenario-based Content Organization $\mathbf{c}$ & Good to Strong \\
\hline 5 & Providing Students Feedback through Systematic Formative Assessment & Strong \\
\hline 6 & Designing In-class Activities to Actively Engage Students $\mathbf{d}$ & Strong \\
\hline 7 & Undergraduate Research & Strong or Fair \\
\hline 8 & Faculty-initiated Approaches to Student-faculty Interactions & Strong \\
\hline
\end{tabular}

${ }^{\mathbf{a}}$ Practices not represented in this study are highlighted in gray; ${ }^{\mathbf{b}}$ In-Class Group Work, Project (group),

Presentation (group), Peer Teaching; ${ }^{\mathbf{c}}$ Real-World Problem Solving, Project (when extended); ${ }^{\mathbf{d}}$ All 10 active learning strategies in current study

Adaptions to Froyd's work were made in order to meet the current study's needs. Firstly, Froyd's original resource constraints description in the "strong/high" evaluative rating category of Table 3, which stated "can be used in most the learning environments in most of the institutions across the country", was made to state "requires little to no additional resource investments" in order to better reflect the other resource constraint descriptions listed in the rubric. Secondly, in Froyd's original evaluation of his eight promising practices, as shown in Table 4, active learning is categorized as one promising practice, "Promising Practice No. 6: Designing In-class Activities to Actively Engage Students". However, the authors noted that while this study's active learning strategies all fit under this sixth promising practice, many of them also share commonalities with Froyd's other practices, which could in turn affect their evaluation ratings. For example, this study's "Real-World Problem Solving" and "Project" (when extended) strategies share commonalities with Froyd's fourth 
promising practice, and when categorized as such, see their implementation ranking decrease from "strong" to "good to strong". In sum, the authors utilized superscripted letters (a, b, c, d), as shown in Table 4, to show how the current study's strategies were matched with Froyd's promising practices.

\section{Findings and Discussions}

Results from the final ten selected active learning strategies are shown in Fig. 1. The following paragraphs discuss each strategy's results, focusing on frequency of student exposure relative to ease of implementation and typical characteristics of active learning environments.

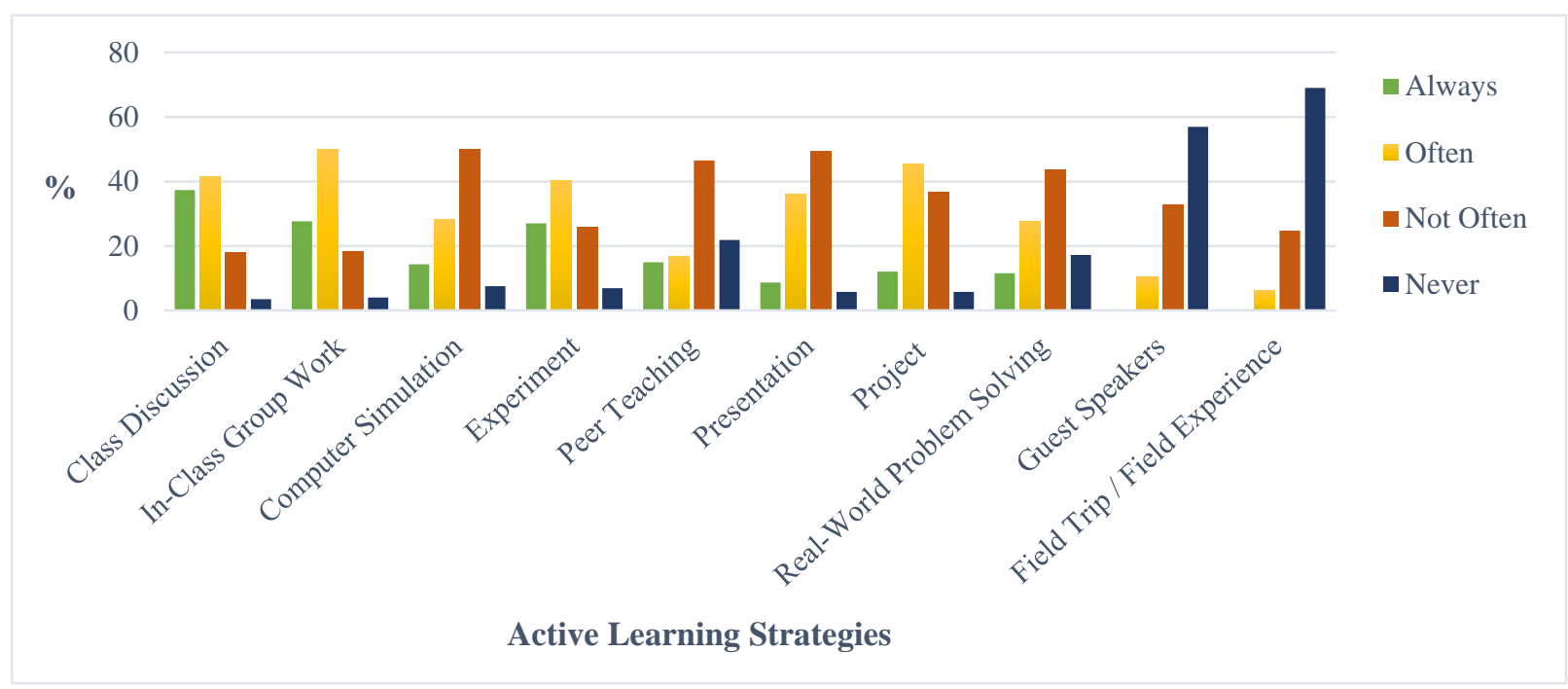

Fig. 1: Active Learning Strategy Exposure Distribution

"Class Discussion" and "In-Class Group Work" are arguably the easiest, most-relevant strategies to implement out of this study's ten strategies, as they require virtually no preparation from the instructor, easily fit into every class, and are relevant to all courses. Thirty-seven percent of students in this study responded that they experience class discussion "always" (i.e., every week), with $41 \%$ stating they experience it "often". Twenty-eight percent of all students stated that they experience in-class group work "always", with $50 \%$ stating that they experience this "often". In both strategies, $22 \%$ of students responded that they experience the strategy either "not often" (i.e., a maximum 3 times per term) or "never". While these percentages point to consistent use of both strategies, an environment characterized by active learning would likely aim for both to occur in most, if not all, class sessions, making these results potentially lower than desired.

The "Computer Simulation" and "Experiment" strategies are characteristic of STEM fields and more relevant to such courses; thus, since participants are Civil Engineering students, one would expect fairly frequent exposure to these strategies. Furthermore, while both rank "strong" in terms of Froyd's implementation standards (both are categorized under Froyd's sixth promising practice in Table 4), these methods may require more instructor preparation than strategies like classroom discussion or in-class group work. Twenty-eight percent of students stated that they experience computer simulations "often", with 50\% stating "not often". The "not often" responses may be seen as low in terms of this strategy's relevance to STEM courses, as students may have only experienced it as little as once during a term. At the same time, it is understood that not every course would require or be able to utilize simulations; thus, these results are not concerning overall. In regards to experiments, $40 \%$ of students stated that they experience this strategy "often", with $26 \%$ stating "not often". As labs are often a part of engineering students' course load, it is likely that respondents considered this strategy only in relation to their lab courses. It should be noted, however, that experiments need not be limited to lab settings (i.e., instructors can demonstrate 
concepts during lectures via experiments), nor do they need to be intensive in terms of time or complexity. As such, there may be room for improvement with this strategy; however, overall, its results are not concerning.

Like classroom discussion and in-class group work, the "Peer Teaching" and "Presentation" strategies involve little instructor preparation, easily fit into every class, and are relevant to all courses. This is because while both can be formally done (i.e., students present a lesson to peers just as instructor does in the case of peer teaching), both can also be carried out informally. For example, peer teaching can be as simple as students helping one another understand concepts while solving a problem during class, and presentations can consist of students presenting their solutions to the class after being given time to work on a problem individually or in groups. Seventeen percent of students stated they experience peer teaching "often" and $47 \%$ stated that they experience it "not often". In the case of presentations, $36 \%$ stated that they experience it "often" and $49 \%$ stated that they experience it "not often". Considering that both strategies rank "strong" in terms of implementation standards and need not be formal in nature, one would expect frequent instances of both strategies occurring in most courses. Furthermore, given that students in active learning environments are to be given ample time to engage in their learning (which often involves discussion, working with others, and sharing ideas), there is likely room for improvement.

The "Project" and "Real-World Problem Solving" strategies can both rank under Froyd's fourth promising practice, which, given its lower implementation ranking, means these strategies can be slightly more difficult to carry out. That being said, this is only the case for projects when they are extended and involve little to no guidance from the instructor; otherwise, projects in general fall under Froyd's sixth promising practice, with a "strong" ranking in terms of implementation standards. Forty-five percent of students stated they experience projects "often", with $37 \%$ stating that they experience it "not often". These results are overall in line with what would be expected in an active learning environment, especially as they are often used as summative assessments, which usually require more planning and aim to assess student learning at the end of learning unit, for example. In the case of real-world problem solving, $28 \%$ stated that they experience it "often", with $44 \%$ stating that they experience it "not often". There was also a noteworthy difference found when looking at the real-world problemsolving strategy's results based on students' year in university; namely, nearly $31 \%$ of fourth- and fifth-year students stated they experience this strategy "often" compared to only $13 \%$ of second-and third-year students. As such, it may be that the fourth- and fifth-year students were including their work on graduation projects when responding, as these projects are specific to students in their last year of university and involve solving real-world problems over the course of an entire year. Yet, as per the strategy description provided in Table 1, inclusion of graduation projects would only qualify as "Real-World Problem Solving" if students were given little to no guidance from instructors. Overall, given the potentially required instructor training and additional resources, it is unclear as to whether students in this survey understood the strategy as intended. If students did understand this strategy and its description, the results are not concerning overall, but they may still be considered to be lower than desired if the UAEU's aim is to foster more independent problem-solving skills in its students.

The "Guest Speakers" and "Field Trip/Field Experience" strategies are seen as beneficial and perhaps even a step beyond typical learning in terms of engaging students and varied learning experiences, but not concerning if lacking. In the case of guest speakers, it is important to note that while part of active learning, not all are active in nature (i.e., some guest speakers incite much student discussion and creative thinking, others do not). Ten percent of students stated they experience guest speakers "often", 33\% stated "not often", and 57\% stated they never experience this. In the case of field trips/field experiences, $6 \%$ stated they experience it "often", $25 \%$ stated "not often", and $69 \%$ stated they never experience this. Given that guest speakers and field trip experiences are likely a rarity in most classrooms, even in active learning environments, results may be higher than what occurs in actuality; however, there are no clear reasons as to why students might have misinterpreted these strategies. Overall, the results for both the guest speaker and field trip/field experience strategies are not concerning, as they are considered to be an area to encourage first-hand, varied student learning opportunities rather than a frequent necessity.

\section{Conclusions}

In light of this study's results, it is important to keep in mind what Froyd and others point out in the literature: active learning strategies i) are relevant for all courses, ii) can be implemented in almost any learning environment, iii) can be adopted initially with small changes on the part of faculty members, and iv) can be used for portions of nearly every class 
session [23]. Findings reveal that while the UAEU's Civil Engineering classrooms are utilizing most of the surveyed active learning strategies, there is still room for improvement, as several of the strategies' frequency of usage can be considered lower than desired relative to the ease of implementation standards suggested by the benchmark selected (i.e., Froyd's work) and the high levels of discussion, collaboration, and problem-solving characteristic of active learning environments [9].

\section{Recommendations}

The authors recommend the following for further related research:

i) Qualitative research: Given the potential misunderstandings that occur even in concise, clearly-written surveys, the authors recommend administering the survey during individual, in-person meetings with students as they complete their survey responses. This would eliminate doubts as to whether students properly understood a concept and provide insight into what kinds of experiences they categorized under each strategy.

ii) Comparing student responses with faculty responses: It would be helpful to compare student answers to instructor's answers in future studies in order to get a clearer, more holistic picture of utilized teaching strategies.

The authors recommend the following in order to promote the understanding and further implementation of active learning strategies:

i) Incentives for faculty prioritization of teaching development: Many universities have centers for teaching and learning that provide workshops, resources, and overall support for its faculty's professional development. The more an institution's faculty take part in these centers and their initiatives, especially teaching workshops, the better. However, it is likely that given the varying demands on faculty time, workshops may go unnoticed or are not prioritized by faculty [24]. As such, the authors recommend more incentives for faculty participation in university centers for teaching and learning. This could involve putting more emphasis on teaching development in promotion criteria, as well as mandating that all faculty participate in a certain number of self-selected teaching workshops per academic year.

ii) New faculty training: It is known that university instructors often must teach themselves to use new teaching practices that they did not experience as students, as graduate and post-doctoral education rarely focus on teaching [12]. Thus, the authors recommend that new faculty be required to take part in training related to teaching that focuses primarily on incorporating active learning strategies in all courses. The training should occur before they begin teaching at an institution.

\section{Acknowledgements}

The authors would like to thank UAEU for funding this research effort under grant number 31 R202 as well as all participating students who were a part of the survey.

\section{References}

[1] A. Mahrous and Ahmed Anis Ahmed, "A cross-cultural investigation of students' perceptions of the effectiveness of pedagogical tools," J. of Studies in Int. Edu., vol. 14, no. 3, pp. 289-306, 2009.

[2] J. A. Burt, "Impact of active learning on performance and motivation in female Emirati students," Learning and Teaching in Higher Edu.: Gulf Perspectives, vol. 1, no. 1, 2004.

[3] K. E. Shaw, A. A. M. A. Badri, and A. Hukul, "Management concerns in United Arab Emirates state schools," Int. J. of Edu. Manag., vol. 9, no. 4, pp. 8-13, 1995.

[4] L. Smith, "Teachers' conceptions of teaching at a gulf university: a starting point for revising teacher development program," Learning and Teaching in Higher Educ.: Gulf Perspectives, vol. 3, no. 1, Jan. 2006.

[5] D. Gokulan, "Education in the UAE: Then, now and tomorrow," Khaleej Times, 15-Apr-2018.

[6] D. Kalambelkar, "Classroom experience: innovations in teaching and learning," Gulf News, 15-May-2019.

[7] J. Kulkarni, "Modern curricula have assorted teaching methods in UAE," Khaleej Times, 19-Jun-2016. 
[8] D. Vassell-Fall, “Arab students' perceptions of strategies to reduce memorization," Arab World English J., vol. 2, no. 3, pp. 48-69, Aug. 2011.

[9] C. C. Bonwell and J. A. Eison, Active Learning: Creating Excitement in the Classroom, $1^{\text {st }}$ ed. Washington, DC: George Washington Univ., ERIC Clearinghouse on Higher Educ., 1991.

[10] S. Freeman, S. Eddy, M. McDonough, M. Smith, N. Okoroafor, H. Jordt, and M. Wenderoth, "Active learning increases student performance in science, engineering, and mathematics," Proc. of the Nat. Academy of Sci., vol. 111, no. 23, pp. 8410-8415, 2014.

[11] J. Bransford, A. Brown, and R. Cocking, How People Learn: Brain, Mind, Experience and School (Expanded Edition). Washington: National Academies Press, 2000.

[12] J. A. Schell and A. C. Butler, "Insights from the science of learning can inform evidence-based implementation of peer instruction," Frontiers in Edu., vol. 3, 2018.

[13] R. M. Felder and R. Brent, "Active learning: an introduction,” ASQ Higher Educ. Brief, vol. 2, no. 4, pp. 1-7, Aug. 2009.

[14] G. Gonzalez, L. Karoly, L. Constant, H. Salem, and C. Goldman, Facing Human Capital Challenges of the 21st Century: Education and Labor Market Initiatives in Lebanon, Oman, Qatar, and the United Arab Emirates. Santa Monica, CA: RAND Corp., 2008.

[15] J. McLaughlin and P. Durrant, "Student learning approaches in the UAE: the case for the achieving domain," Higher Educ. Res. and Dev., vol. 36, no. 1, pp. 158-170, 2016.

[16] S. R. Madsen and B. J. Cook, "Transformative learning: UAE, women, and higher education," J. of Global Responsibility, vol. 1, no. 1, pp. 127-148, 2010.

[17] A. Martin, "An experience of teaching in the United Arab Emirates," English Today, vol. 19, no. 2, pp. 49-54, 2003.

[18] R. Moussly, "Majority of Emirati students are unprepared for university," Gulf News, 27-May-2012.

[19] M. Clarke, "Beyond antagonism? The discursive construction of "new' teachers in the United Arab Emirates," Teaching Edu., vol. 17, no. 3, pp. 225-237, 2006.

[20] S. R. Madsen, "Leadership development in the United Arab Emirates: the transformational learning experiences of women," J. of Leadership \& Organizational Studies, vol. 17, no. 1, pp. 100-110, Sep. 2009.

[21] B. McClusky, "Investigating the relationships between education and culture for female students in tertiary settings in the UAE," Ph.D. thesis, School of Edu., Edith Cowan Univ., Perth, WA, 2017.

[22] UAE Vision, 2018. [Online]. Available: https://www.vision2021.ae/en/uae-vision.

[23] J. E. Froyd, "White paper on promising practices in undergraduate STEM education", presented at the NRC Linking Evidence to Promising Practices in Undergraduate STEM Education Workshop, Washington, DC, USA, June, 2008. Available: https://sites.nationalacademies.org/dbasse/bose/dbasse_080106

[24] R. M. Felder, R. Brent, and M. J. Prince, "Engineering instructional development: programs, best practices, and recommendations," J. of Eng. Edu., vol. 100, no. 1, pp. 89-122, 2011. 